\title{
Tele-Health Intervention for Carers of Dementia Patients-A Systematic Review and Meta-Analysis of Randomized Controlled Trials
}

\author{
Aiyong Zhu ${ }^{1}$, Wenting Cao ${ }^{1}$, Yinghua Zhou ${ }^{1}$, Anan $\mathrm{Xie}^{1}$, Yun Cheng ${ }^{2}$ and Shu-Fen Chu ${ }^{1 *}$ \\ ${ }^{1}$ College of Nursing and Health Management, Shanghai University of Medicine and Health Sciences, Shanghai, China, \\ ${ }^{2}$ Department of Nursing, Huadong Hospital Affiliated to Fudan University, Shanghai, China
}

OPEN ACCESS

Edited by:

Jiehui Jiang,

Shanghai University, China

Reviewed by:

Po-Chun Hsieh,

Taipei Tzu Chi Hospital, Taiwan

Can Sheng,

Capital Medical University, China

*Correspondence:

Shu-Fen Chu

zhusf@sumhs.edu.cn

Received: 30 September 2020 Accepted: 07 January 2021

Published: 10 February 2021

Citation:

Zhu A, Cao W, Zhou Y, Xie A, Cheng Y and Chu S-F (2021) Tele-Health Intervention for Carers of Dementia Patients - A Systematic Review and Meta-Analysis of Randomized Controlled Trials.

Front. Aging Neurosci. 13:612404.

doi: 10.3389/fnagi.2021.612404
Objective: The purpose of this study is to evaluate the major mental health outcomes on dementia patient carers when using psychoeducational programs and psychotherapeutic interventions.

Methods: A meta-analysis was performed with randomized controlled trials of carers' tele-health interventions from the literature inception to December 31, 2019, using PubMed, EMBASE, and CENTRAL databases for articles.

Results: The meta-analysis identified 1,043 results, of which 11 were randomized control trials. Among all 11 randomized control trials, only one study addressed face-to-face contact with online modules of interventions, four studies addressed telephone-based interventions, two studies reported on combined face-to-face contact and phone call interventions, two studies focused on web-based interventions, one study used video and telephone interventions, and one study conducted a computer-telephone integration system of intervention. The updated evidence suggested that there was more efficacy via tele-health interventions in lowering depression for carers of people with dementia. We outlined the delivery formation of intervention to evaluate the effectiveness and processes of major mental health improvements, including depression, burden, anxiety, and quality of life.

Conclusions: In this study, tele-health intervention was shown to significantly lower depression and also lower the risk of mental health impairment. Although there was a significant decrease of depression, there were no significant differences in burden, anxiety, and quality of life. Future researchers are encouraged to carry out larger-scale studies; also, further analysis using a standardized assessment tool is suggested for future multi-component tele-health interventions.

Keywords: tele-health, intervention, carers, dementia, systematic review, meta-analysis

\section{INTRODUCTION}

Studies showed that carers of dementia family members have a poorer quality of life (QoL) (Glueckauf et al., 2007; Häusler et al., 2016; Brown et al., 2019) and higher risk for death by suicide. This risk did not decrease even after the care-recipients were institutionalized or died (Kishita et al., 2018). In 2015, there were 17.7 million informal carers who provided either in-home 
substantial services or unpaid assistance to their family members and friends. Though caregiving can strengthen the relationship between carer and recipient, it can also cause emotional and physical burdens on carers, resulting in higher rates of depression, lower quality of life, and poorer overall health. However, these outcomes might be eliminated when proactively addressing the needs of families and carers. To improve the support systems for carers and the care recipients, it is suggested to have a better understanding of carers and their challenges (Edwards et al., 2020). A UK survey in 2019 found that most carers $(79 \%)$ used one or more types of technology, while distance carers, who do not reside in the same home with the care recipients, used slightly fewer (77\%). There are lots of studies assessing the efficacy of carer interventions on emotional wellbeing (Orgeta et al., 2013; Wagner and Brandt, 2018; Or and Kartal, 2019). However, only a few of these reviewed the effect of intervention by delivery mode for carers of dementia patients, such as tele-health intervention. To develop more cost-effective approaches that meet the needs of people with dementia and their family carers is urgent. Different kinds of interventions could prevent or reduce the negative effect of carers, but use of internet interventions is still very limited (Blom et al., 2013). Some interventions are designed to support carers in their role, such as skills training or education to assist in caring for people living with dementia. Evidence showed that if carers learn to deal more effectively with the stresses of caregiving, their QoL will remain at a higher level. Psychoeducational interventions are the most widely studied, and improvement in level of depression and stress have been reported. Recently, there was one study that conducted a comprehensive review that suggested psychoeducation-skill building interventions show a significant influence on burden when delivered face-to-face (Kishita et al., 2018). This meta-analysis updated the literature on interventions for carers of dementia patients published between 2006 and 2016 and evaluated the efficacy of psychoeducational programs and psychotherapeutic interventions on major mental health outcomes, such as depression, anxiety, burden, and QoL. This study demonstrated strong empirical support for treating anxiety and depression by all modes of delivery (Kishita et al., 2018). Face-to-face intervention is very costly compared to the telehealth-based interventions. Tele-health interventions are much more convenient as carers can receive help when it is necessary, especially in a time such as the COVID-19 pandemic, when social distancing is crucial. Therefore, the purpose of the research is to assess the efficacy of tele-health interventions for carers of dementia patients.

\section{MATERIALS AND METHODS}

\section{Data Sources and Searches}

Inception to December 31, 2019, we developed the search strategy, without language restriction, for PubMed, EMBASE, and CENTRAL for articles. The search terms included caregiver, carer, dementia, cognitive decline, cognitive impairment, web-based intervention, technology intervention, internet intervention, tele-health intervention, and randomized controlled trials. Titles and abstracts were screened by three reviewers independently, while full texts were sourced for relevant articles. Inclusion criteria were assessed independently, and inconsistencies were resolved by consensus. The reference lists of included trials and other published meta-analyses were also reviewed for relevant articles.

\section{Eligibility Criteria}

According to the American Psychiatric Association's Diagnostic and Statistical Manual (DSM-5), dementia is typically diagnosed when acquired cognitive impairment has become severe enough to compromise social and/or occupational functioning. Symptoms of memory loss are caused by a range of cognitive abilities, or a general cognitive decline, and not just memory (Hugo and Ganguli, 2014). Trials were considered eligible if they were randomized clinical trials, comparing the key mental health states of anxiety, depression, and burden, and associated with poor QoL in dementia carers. Trials were required to report at least one of the following forms of intervention: blending face-to-face contact with online modules, telephonebased, combined face-to-face contact and phone calls or webbased intervention, using video and telephone interventions, or a computer-telephone integration system (Table 1). Also, trials were required to report at least one of the following outcomes: symptoms of depression, anxiety, burden, or QoL. Trials that recruited participants with face-to-face intervention only were excluded.

\section{Data Extraction}

Data were collected independently by two authors using a standardized data extraction form, entered into a dedicated database, and checked independently by four authors. The data included study characteristics, baseline demographics of participants, description of the intervention, incidence of dementia, the forms of intervention, main treatment components, and length of each session ( $\mathrm{min}) /$ treatment. We reported outcomes at the point of the longest follow-up. Eleven majority delivery modules of intervention were defined as those in which more than $50 \%$ had tele-health interventions.

\section{Outcomes}

For our primary analysis, we used a hierarchical approach in which we included trials that reported delivery mode of intervention including blending face-to-face contact with online modules, telephone-based, combined face-to-face contact and phone calls, or web-based intervention using video and telephone interventions, or a computer-telephone integration system. We chose this approach to maximize the number of clinical trials included in our primary analysis, while also giving priority to the most tele-health intervention relevant mental health outcomes reported in trials. The main outcomes of this meta-analysis were depression, anxiety, burden, and QoL on follow-up carers of people with dementia. The outcome measures for studies were efficacy carer interventions on anxiety, depression, burden, and quality of life. 
TABLE 1 | Characteristics of included studies.

\begin{tabular}{|c|c|c|c|c|c|c|}
\hline First author & $\begin{array}{l}\text { Year of } \\
\text { publish }\end{array}$ & $\begin{array}{l}\text { Method of } \\
\text { study }\end{array}$ & Diagonosis of care-recipient & Target of population & Format of intervention & Main outcomes \\
\hline Boots L. M. & 2018 & $\mathrm{RCT}$ & $\begin{array}{l}\text { People with mild dementia of all } \\
\text { subtypes (Clinical Dementia } \\
\text { Rating, score } 0.5-1 \text { ) }\end{array}$ & Family caregivers & $\begin{array}{l}\text { Blending face-to-face } \\
\text { contacts with online } \\
\text { modules }\end{array}$ & Depression \\
\hline Tremont G. & 2015 & $\mathrm{RCT}$ & $\begin{array}{l}\text { Most care recipients were } \\
\text { diagnosed with Alzheimer's } \\
\text { disease }\end{array}$ & Family caregivers & Telephone contacts & Depression \\
\hline Prick A. E. & 2015 & $\mathrm{RCT}$ & $\begin{array}{l}\text { Community-dwelling people with } \\
\text { dementia }\end{array}$ & Family caregivers & $\begin{array}{l}\text { Experimental group: home } \\
\text { visits } \\
\text { Comparison group: } \\
\text { information bulletins and } \\
\text { phone calls }\end{array}$ & Depression \\
\hline Cristancho-Lacroix V. & 2015 & $\mathrm{RCT}$ & $\begin{array}{l}\text { Alzheimer's disease was } \\
\text { targeted by this program }\end{array}$ & Informal caregivers & Web-based intervention & Psychologists stress \\
\hline Blom M. M. & 2015 & $\mathrm{RCT}$ & People with dementia & Family caregivers & Internet course MoD & Depression. \\
\hline Glueckauf R. L. & 2012 & $\mathrm{RCT}$ & People with dementia & $\begin{array}{l}\text { African American dementia } \\
\text { caregivers }\end{array}$ & $\begin{array}{l}\text { Combines face-to-face and } \\
\text { telephone-based }\end{array}$ & Depression \\
\hline Gallagher-Thompson D. & 2010 & $\mathrm{RCT}$ & People with dementia & Caregivers & $\begin{array}{l}\text { Using video and telephone } \\
\text { interventions }\end{array}$ & $\begin{array}{l}\text { Depressive symptoms } \\
\text { Stress associated with } \\
\text { memory and behavior } \\
\text { problems }\end{array}$ \\
\hline Gallagher-Thompson D. & 2007 & $\mathrm{RCT}$ & People with dementia & $\begin{array}{l}\text { Female Chinese American } \\
\text { caregivers }\end{array}$ & Telephone contacts & Depressive symptoms \\
\hline Finkel S. & 2007 & $\mathrm{RCT}$ & People with Alzheimer's disease & Caregivers & $\begin{array}{l}\text { Computer-Telephone } \\
\text { Integration System (CTIS) }\end{array}$ & Depression \\
\hline Winter L. & 2006 & $\mathrm{RCT}$ & $\begin{array}{l}\text { People with Alzheimer's disease } \\
\text { or related disorders }\end{array}$ & Female family caregivers & $\begin{array}{l}\text { Telephone-based support } \\
\text { groups }\end{array}$ & Depression \\
\hline Burns R. & 2003 & RCT & People with Alzheimer's disease & Caregivers & $\begin{array}{l}\text { Face-to -face and telephone } \\
\text { contact }\end{array}$ & $\begin{array}{l}\text { General Health and Mental } \\
\text { Health }\end{array}$ \\
\hline
\end{tabular}

\section{Risk of Bias Assessment}

Cochrane risk of bias tool (Higgins et al., 2011) was applied to assess the methodological quality of eligible trials on random sequence generation, allocation concealment, blinded outcome assessment, completeness of outcome data, evidence of selective reporting, and other biases. The risk of bias was independently assessed by two reviewers, while a third reviewer resolved the disagreements. A risk-of-bias summary table was created in Review Manager version 5.3. and the study was considered to be at high risk of bias if two of the domains were rated as high.

\section{Data Synthesis and Analysis}

A descriptive analysis of each trial is provided in Table 1. Outcomes of depression, anxiety, burden, and QoL were estimated for each trial. Weighted pooled treatment effects were calculated using restricted maximum likelihood estimation to fit a random-effects meta-analysis model. A pooled mean difference and $95 \% \mathrm{CI}$ was calculated using a random-effects meta-analysis. If this was not reported, the mean between-group difference reported at follow-up was used.

\section{RESULT}

\section{Study Selection}

The systematic search of articles published from database inception to December 31, 2019, identified 1,043 results.
After title and abstract screening, 26 articles were considered potentially relevant. Twenty studies were included after full- text review. Eleven studies reported the intervention via blending face-to-face contact with online modules $(n=1)$, four were telephone-based $(n=4)$, two combined face-to-face contacts and phone calls $(n=2)$, two used web-based intervention $(n=2)$, one used video and telephone interventions $(n=1)$, and one used a computer-telephone integration system $(n=1)$. These were included in the primary meta-analysis (Figure 1). Seven out of 11 studies were conducted in the United States (Burns et al., 2003; Winter and Gitlin, 2006; Finkel et al., 2007; Gallagher-Thompson et al., 2007, 2010; Glueckauf et al., 2012; Tremont et al., 2015), and the rest were in the Netherlands $(n=3)$ (Blom et al., 2015; Prick et al., 2015; Boots et al., 2018) and France $(n=1)$ (CristanchoLacroix et al., 2015). Of the 11 studies, five studies recruited carers of people with Alzheimer's disease. Most studies involved carers of people with various diagnoses of dementia grouped as a whole. In total, 1,087 participants were enrolled. The mean (SD) age of trial participants was 64.22 (5.4) years old. The publication year ranged from 2003 to 2018. Eleven trials' main outcome measurement were of depression, two trials were of anxiety, six trials were of burden, and two trials were QoL. The most commonly used measurement was the Centre for Epidemiologic Studies Depression scale (CESD). Data were available to calculate the effect size for six of the eleven studies that included burden as one of the outcome measures. The majority of studies used 


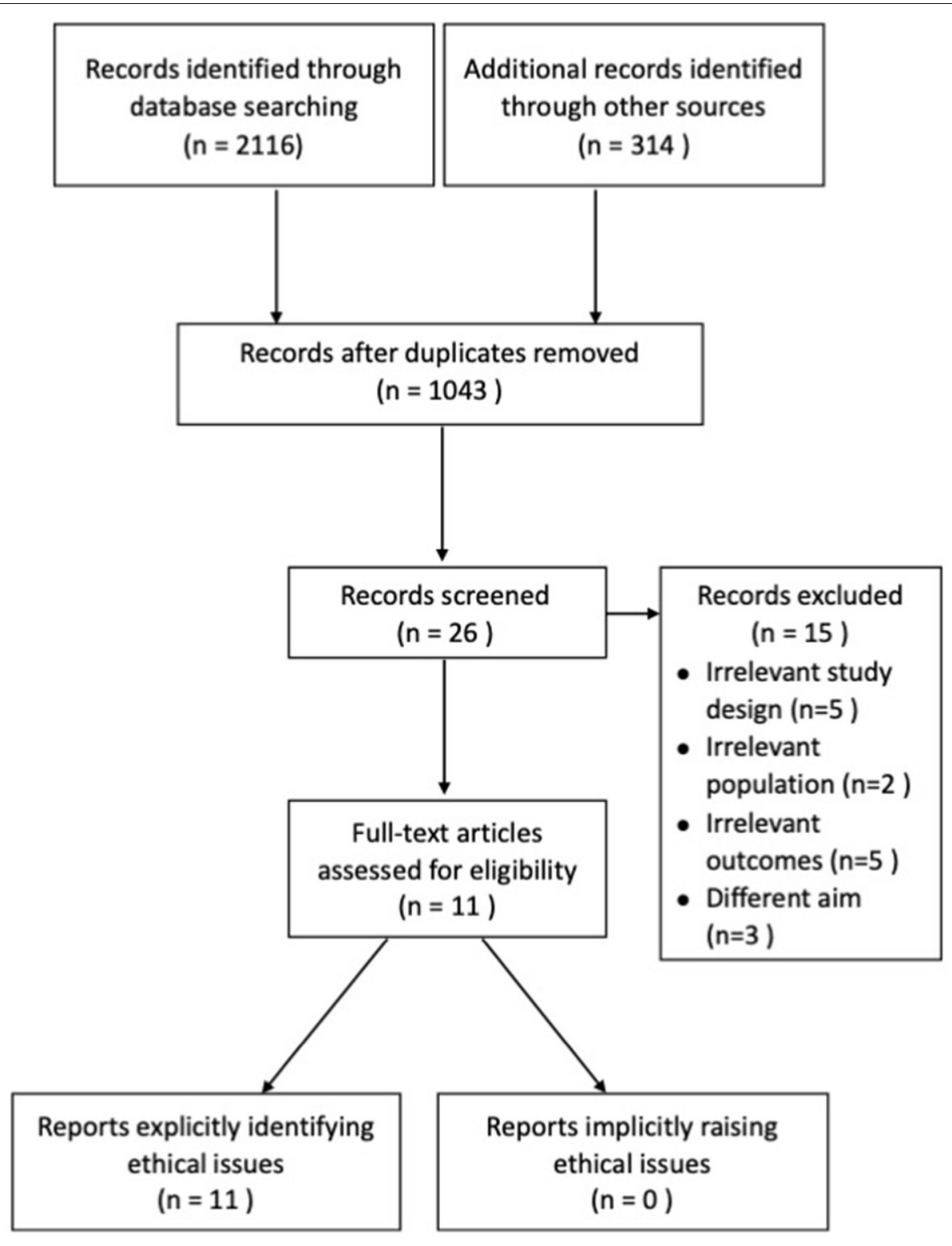

FIGURE 1 | Flow diagram of the studies' selection process.

the Zarit Burden Interview (ZBI). Two studies reported the efficacy of interventions on anxiety. The most commonly used measure was the psychological complaints measure [Hospital Anxiety and Depression Scale-Anxiety (HADS-A)]. Two studies reported the efficacy of interventions on QoL. They used the Investigation Choice Experiments for the Preferences of Older People (ICECAP-O) and Euro-QoL to measure the efficacy.

\section{Study Characteristics}

Blending Face-To-Face Contact With Online Modules and Key Mental Health

This category contained a description of only one trial on followup (81 participants). Carers of people with mild dementia of all subtypes (Clinical Dementia Rating, score 0.5-1) were divided into the intervention group (31 participants) and the control group (37 participants). The primary outcome was self-efficacy and symptoms of depression. Secondary outcomes included QoL and psychological complaints. The main treatment component was a blended care self-management program in combination with face-to-face coaching and tailored web-based modules. The main outcome measure for depression in this study was the CESD scale. The outcome of QoL measure was the Investigation Choice Experiments for the Preferences of Older People (ICECAP-O).

\section{Telephone-Based and Key Mental Health}

Four trials reported telephone-based therapy on follow-up (509 participants). Overall, 270 participants were in the intervention 
group and 239 participants in the control group. Symptoms of depression as primary outcomes were reported in this category. Secondary outcomes included QoL and physiological responses to stress. Two studies involved psychoeducation and skills training of communication as the main treatment component. Other studies provided problem-solving, planning of pleasant activities, and a supportive social network. The main outcome measure for depression in four studies was the CESD scale. The Dutch version of the Revised Memory and Behavior Problem Checklist (RMBPC), used self-rated general health salivary cortisol levels to measure physiological responses to stress. The outcome of the QoL measure was Euro-QoL. Self-Perceived Pressure from Family Care (SPICC) was applied to measure the planning of pleasant activities.

\section{Combines Face-To-Face Contacts and Phone Calls and Key Mental Health}

This category contained a description of two trials on followup (87 participants) and divided the carers of people with either dementia or Alzheimer's disease into the intervention group (43 participants) and the control group (44 participants). Symptoms of depression as the main outcome were reported in this category. One study included physical symptoms, psychosocial resources, and subjective burden secondary outcomes. The other study included general health and mental health and an assessment of how the dementia was manifested for the patient and affected the carer as the secondary outcomes. The main outcome measure for depression in this category was CESD scale. Modified Caregiver Health and Behavior Inventory, Assistance subscale of Interpersonal Support Evaluation List, Caregiver Appraisal Inventory, and modified General Well-Being scale were used to measured secondary outcomes.

\section{Web-Based Intervention and Key Mental Health}

This category contained a description of two trials on followup (294 participants). Overall, 174 participants were in the intervention group and 120 participants in the control group. Symptoms of depression and stress as main outcomes were reported in this category. One study included secondary outcomes such as anxiety. The other study included selfefficacy, burden, perceived health status, and depression as the secondary outcome. The CESD scale and Perceived Stress Scale (PSS-14) were the main two outcome measures for depression and stress. Hospital Anxiety and Depression Scale (HADS-A), Revised Scale for Caregiving Self-Efficacy, Zarit Burden Interview (ZBI), the French version of the Nottingham Health Profile, and Beck Depression Inventory (BDI-II) were used to measure secondary outcomes.

\section{Using Video and Telephone Interventions and Key Mental Health}

This category contained a description of one trial on followup (70 participants). Overall, 36 participants were in the intervention group and 34 participants in the control group. Symptoms of depression and stress as main outcomes were reported in this category and were measured by CESD scale and a Chinese translation of the Revised Memory and Behavior Problems Checklist (RMBPC).

\section{Computer-Telephone Integration System and Key Mental Health}

This category contained a description of one trial on followup (46 participants). Seventeen participants were in the intervention group and 19 participants were in the control group. Symptoms of depression, burden, self-care activities, and social support as outcomes were reported in this category. CESD scale, Revised Memory and Behavior Problems Checklist (RMBPC), Caregiver Health and Health Behaviors scale, and Received Social Support scale for outcomes measurement were performed.

\section{RISK OF BIAS}

The quality of those studies included in our research was assessed by the Cochrane risk of bias summary and no study was excluded due to a high risk bias. All included studies were randomized trials and there were seven studies that described the specific randomization method. The majority of trials $(n=3)$ were single-blind randomized control trials. A randomization sequence was adequately generated in seven studies and 11 adequately concealed allocation. Reporting bias was noted in one trial (Figure 2). In all studies, the quality of detection bias and performance bias was relatively inconsistent, whereas the quality of publication bias was relatively low.

\section{EFFECTS OF INTERVENTIONS}

A random effects model was used for depression. It showed statistically significant high heterogeneity $\left(I^{2}=55 \% ; p=0.01\right)$, which had a large impact on the overall effect size (Blom et al., 2015; Tremont et al., 2015). Overall effective study size for depression was low $[\mathrm{SMD}=-0.34, p=0.01 ; 95 \% \mathrm{CI}=-0.54$ to -0.14 (Figure $3 \mathrm{~A})$ ].

Symptoms of depression with intervention formations of tele-health compared with control was highly correlated with a reduction in carers of people with dementia or $\mathrm{AD}$ with 7.0 vs. $7.5 \%$ over a 4.1 year-follow-up; [OR, 0.93 (95\% CI, 0.88-0.98); ARR, 0.39\% (95\% CI, 0.09-0.68\%)] (Figure 3A). Heterogeneity was low $\left(I^{2}=0.0 \%\right)$.

Anxiety and depression were also analyzed with a random effects model, though no heterogeneity was observed between study size. An overall effect size for anxiety was large $(g=2.10$, $p<0.00001 ; 95 \% \mathrm{CI}=-1.19$ to 2.10 (Figure 3B). There was high heterogeneity between study effect sizes $(Z=0.54$, $\left.p=0.59 ; I^{2}=97\right)$.

The efficacy of interventions on QoL and burden were evaluated with a random effects model, but the heterogeneity was not significant $(g=0.23, p=0.27 ; 95 \% \mathrm{CI}=-0.04$ to 0.50 (Figure 3C) and the heterogeneity between study effect sizes were significantly low $\left(Z=1.69, p=0.09 ; I^{2}=19\right)$ compared with the effect size on burden, which was small $[g=0.04, p=0.72 ; 95 \%$ $\mathrm{CI}=-0.23$ to 0.14 (Figure $3 \mathrm{D})]$. 


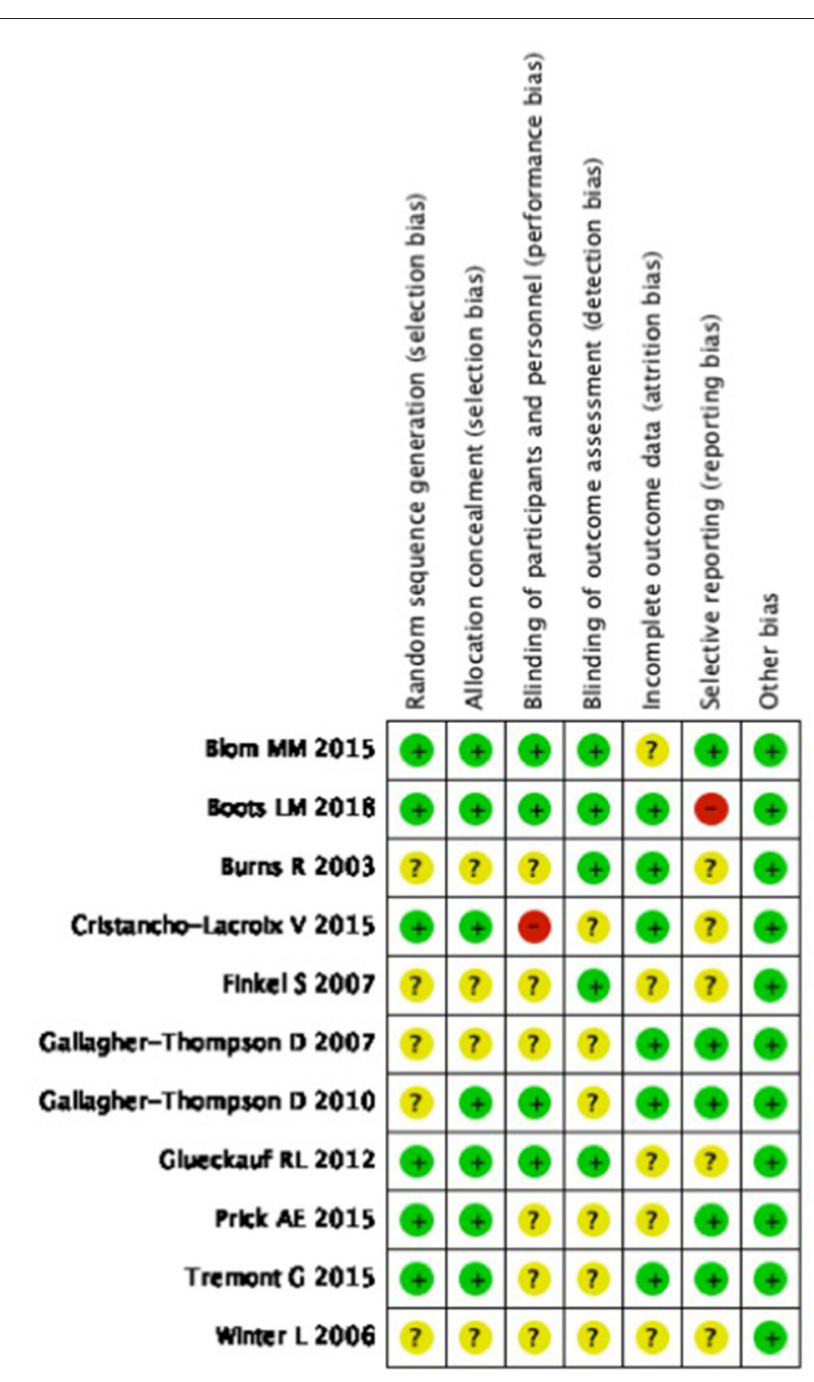

FIGURE 2 | Risk of bias summary: review authors' judgements about each risk of bias item for each included study.

\section{DISCUSSION}

Epidemiologic studies have reported a stronger association between negative states of mental health and carers of people with dementia (Phung et al., 2013). To increase carers' knowledge of the illness, develop problem-solving skills, and facilitate social support through psychoeducational interventions, interventions should be used Technology-based interventions significantly affect burden, anxiety, depression, QoL, and self-efficacy (Frias et al., 2020). Web-based interventions for carers of people with early-stage dementia demonstrated a significant improvement in self-efficacy, mastery, and QoL (Gallagher-Thompson et al., 2010). Both telephone-based and face-to-face technology-based interventions showed improvements in depression, subjective burden, and assistance support in dementia cares (GallagherThompson et al., 2007). There is a significant need for nonpharmacological interventions for persons living with dementia that are easily available, easy to access, and facilitate the use of information and communication technologies (ICTs) (Gilson et al., 2019). This meta-analysis, which included 11 trials with 1,087 participants for the primary outcome analysis, found that was more efficacy via tele-health interventions in lowering depression in carers of people with dementia. We outlined the delivery formation of intervention to evaluate the effectiveness and processes of key mental health improvements, including depression, burden, anxiety, and QoL.

\section{Primary Findings}

Our research showed that depression can be relieved more through tele-health interventions than face-to-face. Steffen et al. reported on a distance intervention carries out with a small sample size by phone and by mail that could prevent the risk of negative effects on mental health [pre-intervention score (SD), 18.9 (4.9), and post-intervention score (SD), 16.1 (3.9)] (Gant et al., 2007). There was a decrease in depression in the intervention that was associated with fewer hospitalizations at 6 months ( $r=0.18, P=0.02$ ) (Tremont et al., 2017). The current study found that carers in the tele-health intervention group had less case-level depression [odds ratio (OR) 0.24, 95\% CI 0.070.76] (Livingston et al., 2014). This was also proven in Zhao et al.'s study in which depression scores dropped an average of 0.23 (95\% CI -0.38 to $-0.07 ; P<0.01$ ) after web-based interventions (Zhao et al., 2019); otherwise, in the study by Kajiyama et al. (2013), it showed evidence-based interventions for carers via the internet for reducing stress was significant $(p=0.017)$ but no significant changes in the bother, depression, or level of life quality. There was no significant effect on depression that was statistically significant effected by Time $(p=0.27)$, Group $(p=0.53)$, Ethnicity $(p=0.34)$, the Group ${ }^{*}$ Time $*$ interaction $(p=0.92)$, or the Group * Ethnicity * Time * interaction $(p=0.08)$ (Czaja et al., 2013). A cross-sectional study reported that carers of $\mathrm{AD}$ dementia patients frequently experienced hypertension $(12.7 \%)$ and insomnia $(11.0 \%)$ but there were no significant differences on depression and other comorbidities (Montgomery et al., 2018). However, the tele-health intervention should be an important measure to help carers of dementia in the future, especially in conjunction with the fast improvement of associated technologies.

\section{Secondary Findings}

One report by Austrom et al. (2015) showed that a weekly web-based video conference support group for carers could relieve their anxiety (mean difference 1.5, improvement 75\%) and burden (mean difference -1.0 , improvement 50\%). Tsolaki et al. (2015) found ICT can not only help patients with cognitive, functional, and behavioral problems, but also support health professionals and carers by reducing their anxiety compared with face-to-face interventions. There is also a meta-analysis that found that web-based interventions significantly improved the anxiety status of carers by -0.32 (95\% CI -0.50 to -0.14 ; $P=0.0005$ ) (Zhao et al., 2019). However, McKechnie et al. (2014) reported no change in depression or anxiety over the 12-week study period via online peer support. In one study, carers who had access to a website improved their confidence while role 
A

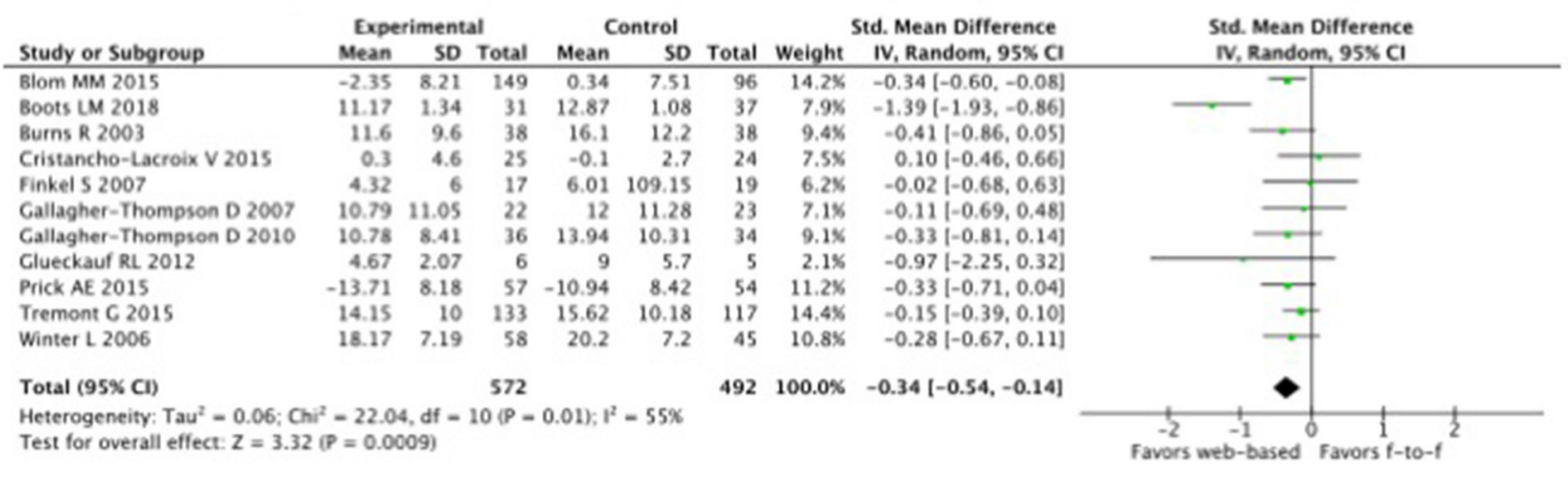

B

\begin{tabular}{|c|c|c|c|c|c|c|c|c|c|}
\hline \multirow[b]{2}{*}{ Study or Subgroup } & \multicolumn{3}{|c|}{ Experimental } & \multicolumn{3}{|c|}{ Control } & \multicolumn{2}{|r|}{ Std. Mean Difference } & \multirow{2}{*}{$\begin{array}{l}\text { Std. Mean Difference } \\
\text { IV, Random, } 95 \% \mathrm{Cl}\end{array}$} \\
\hline & Mean & SD & Total & Mean & SD & Total & Weight & IV, Random, 95\% CI & \\
\hline Blom MM 2015 & -1.69 & 3.26 & 149 & -0.47 & 3.41 & 96 & $51.0 \%$ & $-0.37[-0.62,-0.11]$ & 맘 \\
\hline Boots LM 2018 & 6.73 & 0.63 & 31 & 5.91 & 0.61 & 37 & $49.0 \%$ & $1.31[0.78,1.84]$ & 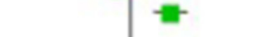 \\
\hline Total $(95 \% \mathrm{Cl})$ & & & 180 & & & 133 & $100.0 \%$ & $0.45[-1.19,2.10]$ & \\
\hline \multicolumn{9}{|c|}{$\begin{array}{l}\text { Heterogeneity: } \operatorname{Tau}^{2}-1.36 ; \mathrm{Chi}^{2}-31.17, \mathrm{df}=1(\mathrm{P}<0.00001) ; \mathrm{I}^{2}=97 \% \\
\text { Test for overall effect: } Z=0.54(P=0.59)\end{array}$} & 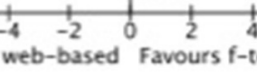 \\
\hline
\end{tabular}

C

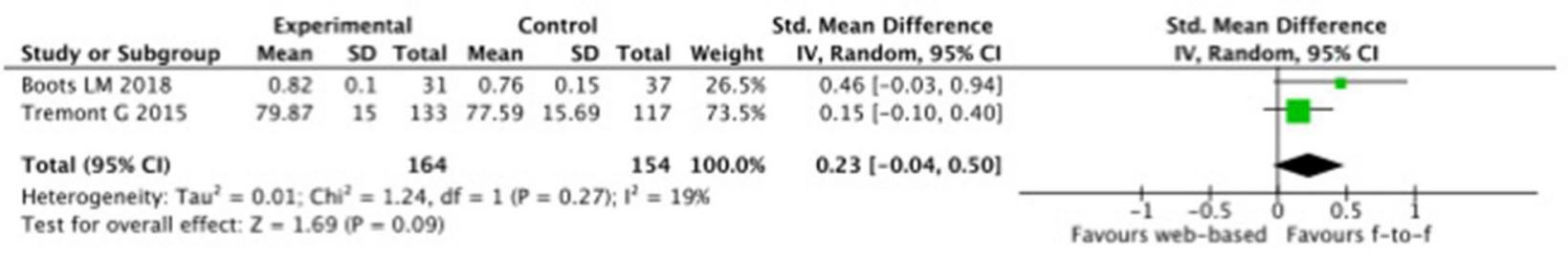

D

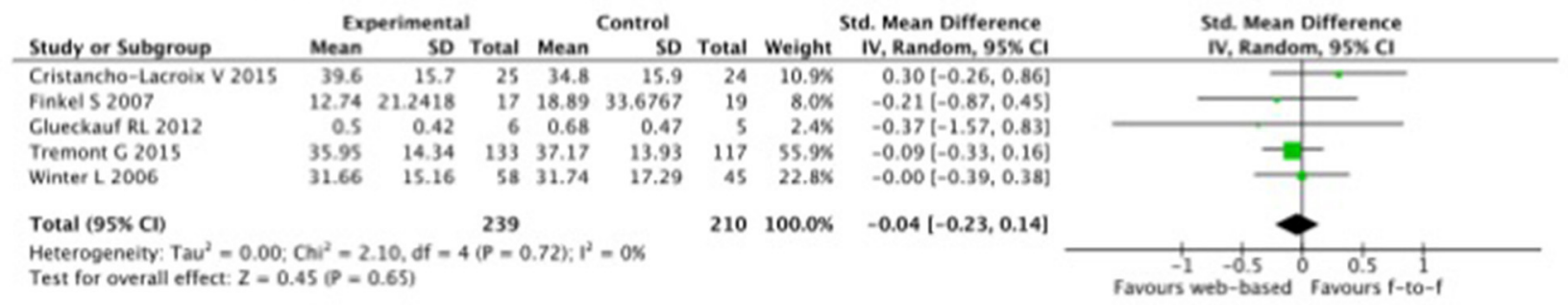

FIGURE 3 | Effect sizes (Hedge's g) derived from studies examining the tele-health intervention of carers. (A) Depression. (B) Anxiety. (C) Quality of life. (D) Burden.

strain, anxiety, and depression were decreased, although some of them were not significant (Zimmerman et al., 2018). However, a small sample size, low test efficiency, and a high rate of loss to follow-up over time limits this study and further research is needed to draw a conclusion.

\section{Burden}

Our study showed that the mental health burden would be reduced through tele-health intervention. Some studies showed a correlation between scores on depression, anxiety, and sleep quality assessments and carers' burden (Coffman et al., 2017). Online contact with a professional led to relief in burden and strain for those carers that appreciated personalized practical advice and emotional support (Hopwood et al., 2018). However, not many studies support this result. Parker et al. (2008) performed a meta-analysis study that indicated that there were no significant effects from any of the interventions. Therefore, the major outcome for web-based learning courses was the increase 
in knowledge. No effects were found on the relief of burden (Hattink et al., 2015).

\section{Quality of Life}

Our study revealed that tele-health interventions could improve quality of life for carers of dementia patients.

Although there was one study that indicated that quality of life was only moderate $(\mathrm{SD}=8.21)$ and negatively correlated with burden $(r=-32, p=0.01)$ and depression $(r=-0.296$, $p<0.05$ ) (Papastavrou et al., 2014), the findings from Bartfay and Bartfay (2013) showed similar levels of QOL between carers who used community-based interventions. Another systemic metaanalysis showed the effectiveness of IT interventions in the carers of elderly dementia both improving the quality of life and effects on behavior (such as less falling) (Nijhof et al., 2009). However, Duggleby et al. (2018) reported no significant differences from web-based interventions on health-related quality of life, neither for carers of community-living persons with Alzheimer's disease, nor for related dementia.

\section{Quality of the Included Studies}

All results of the quality assessment for the included studies were rated as medium, which explained the variation in many domains, such as theoretical model selection, intervention format, and evaluation tools. It also increased the difficulty in assessing the risk of bias in many areas, which resulted in inconsistent results. There is more and more evidence proving the feasibility of tele-health multicomponent interventions and suggesting the most useful and least expensive intervention components or platforms. Further research on carer-focused interventions to improve their mental health is suggested in the future.

\section{LIMITATIONS}

There are a few limitations that may lessen the credibility of our study. First, the study was not assessed by a standardized

\section{REFERENCES}

Austrom, M. G., Geros, K. N., Hemmerlein, K., McGuire, S. M., Gao, S., Brown, S. A., et al. (2015). Use of a multiparty web based videoconference support group for family caregivers: innovative practice. Dementia 14, 682-690. doi: $10.1177 / 1471301214544338$

Bartfay, E., and Bartfay, W. J. (2013). Quality-of-life outcomes among Alzheimer's disease family caregivers following community-based intervention. West. J. Nurs. Res. 35, 98-116. doi: 10.1177/0193945911400763

Blom, M. M., Bosmans, J. E., Cuijpers, P., Zarit, S. H., and Pot, A. M. (2013). Effectiveness and cost-effectiveness of an internet intervention for family caregivers of people with dementia: design of a randomized controlled trial. BMC Psychiatry 13:17. doi: 10.1186/1471-244X-13-17

Blom, M. M., Zarit, S. H., Groot Zwaaftink, R. B., Cuijpers, P., and Pot, A. M. (2015). Effectiveness of an internet intervention for family caregivers of people with dementia: results of a randomized controlled trial. PLOS ONE 10:e116622. doi: 10.1371/journal.pone.0116622

Boots, L. M., de Vugt, M. E., Kempen, G. I., and Verhey, F. R. (2018). Effectiveness of a blended care self-management program for caregivers of people with early-stage dementia. (Partner in balance): randomized controlled trial. J. Med. Internet Res. 20:e10017. doi: 10.2196/10017 tool, and only limited variables were analyzed. Second, only the USA, Dutch, and France were included, which may limit the ability to conclude the result in other nationalities. Third, there were large differences in the usage of assistive technology, outcome measures, and the quality of studies. All of these created difficulties in comparing results across reviews.

\section{CONCLUSIONS}

In this meta-analysis of randomized clinical trials, depression lowering with tele-health interventions compared with a controlled group was significantly associated with a lower risk of incident mental health impairment. Although there was a significant decrease in depression, there were no significant differences in burden, anxiety, or quality of life. More rigorous methods and larger-scale, higher-quality studies and multicomponent tele-health interventions are suggested in the future to analyze the outcome in further detail using a standardized assessment tool.

\section{DATA AVAILABILITY STATEMENT}

The raw data supporting the conclusions of this article will be made available by the authors, without undue reservation.

\section{AUTHOR CONTRIBUTIONS}

All authors listed have made a substantial, direct and intellectual contribution to the work, and approved it for publication.

\section{ACKNOWLEDGMENTS}

The authors acknowledge the contributions of Professor Chiehfeng Chen, Taipei Medical University who aided the efforts of the authors.
Brown, A., Page, T. E., Daley, S., Farina, N., Basset, T., Livingston, G., et al. (2019). Measuring the quality of life of family carers of people with dementia: development and validation of C-DEMQOL. J. Qual. Life Res. 28:8. doi: 10.1007/s11136-019-02186-w

Burns, R., Nichols, L. O., Martindale-Adams, J., Graney, M. J., and Lummus, A. (2003). Primary care interventions for dementia caregivers: 2year outcomes from the REACH study. Gerontologist 43, 547-555. doi: 10.1093/geront/43.4.547

Coffman, I., Resnick, H. E., and Lathan, C. E. (2017). Behavioral health characteristics of a technology-enabled sample of Alzheimer's caregivers with high caregiver burden. Mhealth 3:36. doi: 10.21037/mhealth.20 17.08.01

Cristancho-Lacroix, V., Wrobel, J., Cantegreil-Kallen, I., Dub, T., Rouquette, A., and Rigaud, A. S. (2015). A web-based psychoeducational program for informal caregivers of patients with Alzheimer's disease: a pilot randomized controlled trial. J. Med. Internet Res. 17:e117. doi: 10.2196/jmir.3717

Czaja, S. J., Loewenstein, D., Schulz, R., Nair, S. N., and Perdomo, D. (2013). A Videophone psychosocial intervention for dementia caregivers. Am. J. Geriatr. Psychiatry 21, 1071-1081. doi: 10.1016/j.jagp.2013.02.019

Duggleby, W., Ploeg, J., McAiney, C., Peacock, S., Fisher, K., Ghosh, S., et al. (2018). Web-based intervention for family carers of persons with 
dementia and multiple chronic conditions (my tools 4 care): pragmatic randomized controlled trial. J. Med. Internet Res. 20:e10484. doi: 10.2196/ 10484

Edwards, V. J., Bouldin, E. D., Taylor, C. A., Olivari, B. S., and McGuire, L. C. (2020). Characteristics and health status of informal unpaid caregivers - 44 states, district of Columbia, and Puerto Rico, 2015-2017. MMWR Morbid. Mortal. Wkly. Rep. 69, 183-188. doi: 10.15585/mmwr.mm $6907 \mathrm{a} 2$

Finkel, S., Czaja, S. J., Schulz, R., Martinovich, Z., Harris, C., and Pezzuto, D. (2007). E-care: a telecommunications technology intervention for family caregivers of dementia patients. Am. J. Geriatr. Psychiatry 15, 443-448. doi: 10.1097/JGP.0b013e3180437d 87

Frias, C. E., Garcia-Pascual, M., Montoro, M., Ribas, N., Risco, E., and Zabalegui, A. (2020). Effectiveness of a psychoeducational intervention for caregivers of people with dementia with regard to burden, anxiety and depression: a systematic review. J. Adv. Nurs. 76, 787-802. doi: 10.1111/jan. 14286

Gallagher-Thompson, D., Gray, H. L., Tang, P. C., Pu, C. Y., Leung, L. Y., Wang, P. C., et al. (2007). Impact of in-home behavioral management versus telephone support to reduce depressive symptoms and perceived stress in Chinese caregivers: results of a pilot study. Am. J. Geriatr. Psychiatry 15, 425-434. doi: 10.1097/JGP.0b013e3180 312028

Gallagher-Thompson, D., Wang, P. C., Liu, W., Cheung, V., Peng, R., China, D., et al. (2010). Effectiveness of a psychoeducational skill training DVD program to reduce stress in Chinese American dementia caregivers: results of a preliminary study. Aging Ment. Health 14, 263-273. doi: 10.1080/13607860903420989

Gant, J. R., Steffen, A. M., and Lauderdale, S. A. (2007). Comparative outcomes of two distance-based interventions for male caregivers of family members with dementia. Am. J. Alzheimers Dis. Other Dement. 22, 120-128. doi: 10.1177/1533317506298880

Gilson, A., Dodds, D., Kaur, A., Potteiger, M., and Ford Ii, J. H. (2019). Using computer tablets to improve moods for older adults with dementia and interactions with their caregivers: pilot intervention study. JMIR Form. Res. 3:e14530. doi: 10.2196/14530

Glueckauf, R. L., Davis, W. S., Willis, F., Sharma, D., Gustafson, D. J., Hayes, J., et al. (2012). Telephone-based, cognitive-behavioral therapy for African American dementia caregivers with depression: initial findings. Rehabil. Psychol. 57, 124-139. doi: 10.1037/a0028688

Glueckauf, R. L., Jeffers, S. B., Sharma, D., Massey, A. J., Davis, W. S., Wesley, L. M., et al. (2007). Telephone-based cognitive-behavioral intervention for distressed rural dementia caregivers. Clin. Gerontol. 31, 21-41. doi: 10.1300/J018v31n01_03

Hattink, B., Meiland, F., van der Roest, H., Kevern, P., Abiuso, F., Bengtsson, J., et al. (2015). Web-based STAR E-learning course increases empathy and understanding in dementia caregivers: results from a randomized controlled trial in the Netherlands and the United Kingdom. J. Med. Internet Res. 17:e241. doi: 10.2196/jmir.4025

Häusler, A., Sánchez, A., Gellert, P., Deeken, F., Rapp, M. A., and Nordheim, J. (2016). Perceived stress and quality of life in dementia patients and their caregiving spouses: does dyadic coping matter? J. Int. Psychogeriatr. 28:11. doi: 10.1017/S1041610216001046

Higgins, J. P., Altman, D. G., Gøtzsche, P. C., Jüni, P., Moher, D., Oxman, A. D., et al. (2011). The cochrane collaboration's tool for assessing risk of bias in randomised trials. BMJ 343:d5928. doi: 10.1136/bmj. d5928

Hopwood, J., Walker, N., McDonagh, L., Rait, G., Walters, K., Iliffe, S., et al. (2018). Internet-based interventions aimed at supporting family caregivers of people with dementia: systematic review. J. Med. Internet Res. 20:e216. doi: 10.2196/jmir.9548

Hugo, J., and Ganguli, M. (2014). Dementia and cognitive impairment: epidemiology, diagnosis, and treatment. Clin. Geriatr. Med. 30, 421-442. doi: 10.1016/j.cger.2014.04.001

Kajiyama, B., Thompson, L. W., Eto-Iwase, T., Yamashita, M., Di Mario, J., Marian Tzuang, Y., et al. (2013). Exploring the effectiveness of an internet-based program for reducing caregiver distress using the iCare
Stress Management e-Training Program. Aging Ment. Health 17, 544-554. doi: 10.1080/13607863.2013.775641

Kishita, N., Hammond, L., Dietrich, C. M., and Mioshi, E. (2018). Which interventions work for dementia family carers?: an updated systematic review of randomized controlled trials of carer interventions. Int. Psychogeriatr. 30, 1679-1696. doi: 10.1017/S1041610218000947

Livingston, G., Barber, J., Rapaport, P., Knapp, M., Griffin, M., Romeo, R., et al. (2014). START (STrAtegies for RelaTives) study: a pragmatic randomised controlled trial to determine the clinical effectiveness and cost-effectiveness of a manual-based coping strategy programme in promoting the mental health of carers of people with dementia. Health Technol. Assess. 18, 1-242. doi: 10.3310/hta18610

McKechnie, V., Barker, C., and Stott, J. (2014). The effectiveness of an internet support forum for carers of people with dementia: a pre-post cohort study. J. Med. Internet Res. 16:e68. doi: 10.2196/ jmir.3166

Montgomery, W., Goren, A., Kahle-Wrobleski, K., Nakamura, T., and Ueda, K. (2018). Alzheimer's disease severity and its association with patient and caregiver quality of life in Japan: results of a community-based survey. BMC Geriatr. 18:141. doi: 10.1186/s12877-0180831-2

Nijhof, N., van Gemert-Pijnen, J. E., Dohmen, D. A., and Seydel, E. R. (2009). Dementia and technology. A study of technology interventions in the healthcare for dementia patients and their caregivers. Tijdschr. Gerontol. Geriatr. 40, 113-132. doi: 10.1007/BF03 079573

Or, R., and Kartal, A. (2019). Influence of caregiver burden on well-being of family member caregivers of older adults. Psychogeriatrics 19, 482-490. doi: $10.1111 /$ psyg. 12421

Orgeta, V., Lo Sterzo, E., and Orrell, M. (2013). Assessing mental wellbeing in family carers of people with dementia using the WarwickEdinburgh mental well-being scale. Int. Psychogeriatr. 25, 1443-1451. doi: $10.1017 /$ S1041610213000835

Papastavrou, E., Andreou, P., Middleton, N., Papacostas, S., and Georgiou, I. K. (2014). Factors associated with quality of life among family members of patients with dementia in Cyprus. Int. Psychogeriatr. 26, 443-452. doi: $10.1017 /$ S104161021300224X

Parker, D., Mills, S., and Abbey, J. (2008). Effectiveness of interventions that assist caregivers to support people with dementia living in the community: a systematic review. JBI Libr. Syst. Rev. 6, 484-544. doi: 10.11124/jbisrir-20 08-217

Phung, K. T., Waldorff, F. B., Buss, D. V., Eckermann, A., Keiding, N., Rishøj, S., et al. (2013). A three-year follow-up on the efficacy of psychosocial interventions for patients with mild dementia and their caregivers: the multicentre, rater- blinded, randomised Danish Alzheimer Intervention Study (DAISY). BMJ Open 3:e003584. doi: 10.1136/bmjopen-2013003584

Prick, A. E., de Lange, J., Twisk, J., and Pot, A. M. (2015). The effects of a multi-component dyadic intervention on the psychological distress of family caregivers providing care to people with dementia: a randomized controlled trial. Int. Psychogeriatr. 27, 2031-2044. doi: 10.1017/S1041610215 $00071 \mathrm{X}$

Tremont, G., Davis, J. D., Ott, B. R., Galioto, R., Crook, C., Papandonatos, G. D., et al. (2017). Randomized trial of the family intervention: telephone trackingcaregiver for dementia caregivers: use of community and healthcare resources. J. Am. Geriatr. Soc. 65, 924-930. doi: 10.1111/jgs.14684

Tremont, G., Davis, J. D., Papandonatos, G. D., Ott, B. R., Fortinsky, R. H., Gozalo, P., et al. (2015). Psychosocial telephone intervention for dementia caregivers: a randomized, controlled trial. Alzheimers Dement. 11, 541-548. doi: 10.1016/j.jalz.2014.05.1752

Tsolaki, M., Zygouris, S., Lazarou, I., Kompatsiaris, I., Chatzileontiadis, L., Votis, C., et al. (2015). Our experience with informative and communication technologies (ICT) in dementia. Hell. J. Nucl. Med. 18 131-139.

Wagner, M., and Brandt, M. (2018). Long-term care provision and the wellbeing of spousal caregivers: an analysis of 138 European regions. J. Gerontol. B Psychol. Sci. Soc. Sci. 73, E24-E34. doi: 10.1093/geronb/gbx133 
Winter, L., and Gitlin, L. N. (2006). Evaluation of a telephone-based support group intervention for female caregivers of community-dwelling individuals with dementia. Am. J. Alzheimers Dis. Other Dement. 21, 391-397. doi: $10.1177 / 1533317506291371$

Zhao, Y., Feng, H., Hu, M., Hu, H., Li, H., Ning, H., et al. (2019). Web-based interventions to improve mental health in home caregivers of people with dementia: meta-analysis. J. Med. Internet Res. 21:e13415. doi: 10.2196/13415

Zimmerman, S., Sloane, P. D., Ward, K., Beeber, A., Reed, D., Lathren, C., et al. (2018). Helping dementia caregivers manage medical problems: benefits of an educational resource. Am. J. Alzheimers Dis. Other Dement. 33, 176-183. doi: $10.1177 / 1533317517749466$
Conflict of Interest: The authors declare that the research was conducted in the absence of any commercial or financial relationships that could be construed as a potential conflict of interest.

Copyright (c) 2021 Zhu, Cao, Zhou, Xie, Cheng and Chu. This is an open-access article distributed under the terms of the Creative Commons Attribution License (CC BY). The use, distribution or reproduction in other forums is permitted, provided the original author(s) and the copyright owner(s) are credited and that the original publication in this journal is cited, in accordance with accepted academic practice. No use, distribution or reproduction is permitted which does not comply with these terms. 